\title{
A FENOMENOLOGIA DO ENSINO DE FILOSOFIA COMO HERMENÊUTICA DA SALA DE AULA
}

\author{
Gustavo Silvano Batista* \\ Leonardo Henrique Morais Martins*
}

\begin{abstract}
Resumo: O presente artigo pretende discutir o ensino de filosofia a partir das reflexões de Martin Heidegger, ressaltando seu caráter fenomenológico. Neste sentido, ao tratar a relação entre ensino e aprendizado no horizonte da sala de aula, buscamos compreender a relação entre docente e discente como um caminho existencial no qual todo conhecimento é possível de ser aprendido, à medida que a própria compreensão hermenêutica se dá nas atitudes reflexivas docente e discente. Assim, compreendemos a sala de aula como um ambiente especialmente hermenêutico, pois possibilita o questionamento filosófico para além da transmissão de conhecimentos filosóficos historicamente estabelecidos, abrindo espaço para uma reflexão mais fundamental e, por essa razão, existencial.
\end{abstract}

Palavras chaves: Heidegger; Ensino de filosofia; Aprendizado; Disposição; Autenticidade.

Resumen: Este artículo tiene como objetivo discutir la enseñanza de la filosofía basada en las reflexiones de Martin Heidegger, destacando su carácter fenomenológico. En este sentido, cuando se trata de la relación entre la enseñanza y el aprendizaje en el aula, buscamos entender la relación entre el maestro y el alumno como un camino existencial en el que se puede aprender todo el conocimiento, ya que la comprensión hermenéutica misma ocurre en actitudes reflexivas de profesor y alumno. Por lo tanto, entendemos el aula como un entorno especialmente hermenéutico, ya que permite el cuestionamiento filosófico más allá de la transmisión del conocimiento filosófico establecido históricamente, abriendo espacio para una reflexión más fundamental y, por esta razón, existencial.

Palabras claves: Heidegger; Enseñanza de la filosofía; Aprendizaje; Disposición; Autenticidad.

\section{Introdução}

Refletir sobre o processo de ensinoaprendizagem, interpretado à luz do pensamento de Heidegger, é uma oportunidade de analisar o caráter fenomenológicoexistencial desse processo, concentrando-se no 'interrogar' como o ponto de relação de cunho fenomenológico entre professor $e$ aluno, propondo assim uma hermenêutica fenomenológico-existencial das atitudes do-

\footnotetext{
* Doutor em Filosofia pela PUC-RJ. Professor do Departamento de Filosofia da UFPI. Professor Permanente do PPGFIL/UFPI e Colaborador do PROFFILO/ UFPR - Núcleo UFT.

E-mail: gustavosilvano@ufpi.edu.br.

** Mestre em Filosofia pela UFT. Professor de Filosofia no Ensino Médio no Estado do Tocantins. E-mail: leonardoloughan@gmail.com.
}

cente e discente, na tentativa de questionar $e$ sustentar o "como" que conduz a pergunta. Deste modo, o presente artigo pretende apresentar, na perspectiva de Heidegger, o ensino de filosofia, tomando o caráter fenomenológico da relação docente/discente, na tentativa de pensar uma hermenêutica da sala de aula.

Compreender o ensino de filosofia na escola como um processo de transmissão de conhecimentos históricos da filosofia ocidental ou, ainda, como o simples exercício da reflexão pessoal sobre algum assunto não faz justiça ao próprio exercício do pensamento. $\mathrm{O}$ retorno a Heidegger parte de uma certa postura teórica do autor, na tentativa de repensar a filosofia como um momento no

BATISTA, Gustavo Silvano; MARTINS, Leonardo Henrique Morais. A fenomenologia do ensino de filosofia como hermenêutica da sala de aula. Revista Sul-Americana de Filosofia e Educação. Número 34: nov. 2020 - abril 2021, p. 127-139. DOI: https://doi.org/10.26512/resafe.v2i34.35136 
qual temos oportunidade de realizar um questionamento radical, que reconsidere a própria estrutura histórica da filosofia ocidental; e que também reconsidere o exercício do pensamento como uma habilidade que leva em conta uma questão única e persistente - a questão do ser, pergunta esquecida - tomada a partir da própria situação daquele que questiona.Nesta perspectiva, retornaremos ao texto "Que é isto - a filosofia?", ensaio de 1955, onde Heidegger discute a problemática do processo de predicação e objetivação da filosofia, concentrando-se em uma hermenêutica do modo-de-ser do perguntar. Em seguida, abordaremos as reflexões feitas pelo autor no texto "Que é uma coisa?", publicado em 1962, onde Heidegger afirma que o ensino de filosofia não é somente o exercício das ferramentas e meios didáticos a viabilizar a correta e eficaz transmissão de conteúdos. Mas é importante dar um passo à frente.

\section{A hermenêutica do perguntar ou o modo que a pergunta conduz}

O ponto de partida interrogativo no ensaio "Que é isto - a filosofia?" está dividido inicialmente na ênfase em "ist", "das" $e$ "Philosophie". Porém, antes de designar o objeto de investigação, a filosofia, Heidegger destaca e problematiza os processos de predicação e de objetivação. Essa questão é a fonte e o núcleo de sua reflexão. Assim, o autor afirma que o "ist" é um postulado da existência e, por isso, é anterior a qualquer interrogação significativa, sendo também crucial para qualquer o estudo de qualquer questão.

\begin{abstract}
Devemos tentar determinar mais exatamente a questão. Desta maneira, levaremos o diálogo para direção segura. Procedendo assim, o diálogo é conduzido a um caminho. Digo: a um caminho. Assim concedemos que este não é o único caminho. Deve ficar mesmo em aberto se o caminho para o qual desejaria chamar a atenção, no que segue, é na verdade um caminho que nos permite levantar a questão e respondê-la (HEIDEGGER, 1973, p. 211).
\end{abstract}

Talvez pudéssemos considerar o título do texto nos seguintes termos: "O que é perguntar - o que é esta coisa, a filosofia?" Notamos que logo de início Heidegger nos coloca duas questões: a primeira será tratada diretamente no texto, sendo considerada pelo autor, como a questão filosóficohistórica central do pensamento ocidental. A segunda - o que é questionar? - é demonstrada no decorrer da conferência em seu próprio modo de discursar e problematizar a pergunta fundamental.

Heidegger compreende a filosofia enquanto um exercício reflexivo, demora-se nele, submete-se ao seu comportamento $e$ leis, ou, em outras palavras, busca recuperar o modo de ser do filosofar para além do trabalho técnico do filósofo em seu escritório. Para explicar melhor esse argumento, o autor retorna à questão da diferença ontológica. Para ele, somente tendo em vista a diferença entre ser e entes pode-se abrir um caminho genuíno para o pensamento, mesmo que isso contribua para uma crítica radical à própria filosofia. Ao nos apresentar a questão, Heidegger afirma que a filosofia é, estruturalmente, direcionada a procurar o que é o ente enquanto "é", ou seja, entificando o 
ser; por isso, tornar-se uma tarefa compreender o caminho da filosofia como a busca do modo de ser do ente, ou seja, o ser que não pode ser entificado.

O texto de Heidegger convida-nos todo tempo nessa busca e caminho, desde a origem, do sentido mais próprio e inicial do filosofar humano, que não pode se confundir com a afirmação de algum sistema filosófico. Logo no começo do texto o autor nos chama a atenção para não vagarmos através de representações arbitrárias a respeito da filosofia, para isso ele nos indica a busca de um caminho seguro e cuidadoso para o diálogo. Heidegger ressalta que o caminho não apenas nos mantém fora do exercício histórico da filosofia, mas um caminho que nos faz penetrar cada vez mais na questão, conforme ele mesmo observa:

Que é isto - a filosofia? Falamos sobre a filosofia. Perguntando desta maneira, permanecemos, num ponto acima da filosofia e isto quer dizer fora dela. Porém, a meta de nossa questão é penetrar na filosofia, demorarmo-nos nela, submeter nosso comportamento às suas leis, quer dizer, "filosofar" O caminho de nossa discussão deve ter por isso não apenas uma direção bem clara, mas esta direção deve, ao mesmo tempo, oferecer-nos também a garantia de que nos movemos no âmbito da filosofia, e não fora dela (HEIDEGGER, 1973, p. 211).

Assim, segundo Heidegger, não é possível encontrar resposta sobre a questão através de enunciados e estudos históricos sobre as definições de filosofia, mas, ao contrário, essa resposta só será encontrada através do diálogo com aquilo que nos transmi- tiu como modo de ser dos entes. O texto de Heidegger pretende sublinhar o postulado segundo o qual esse caminho é apenas uma possibilidade. O esforço do pensamento de Heidegger está justamente em mostrar que o processo de empreender - e a noção de "a caminho" - , não só precede a noção de "atingir-se" uma meta, seja ela qual for.

Para conhecer, segundo o filósofo, o indivíduo (Dasein) deve ser tocado por uma disposição (Befindlichkeit), o pathos, que o encaminhe numa dinâmica básica de ensinoaprendizagem, sendo que o sucesso da tarefa do conhecimento não se resume apenas à apreensão do aluno dos conteúdos trazido pelo professor, e sim, se dá e se desvela quando o aluno sintoniza com o fundamento da filosofia e, a partir daí, pensa, filosofa e aprende. A filosofia não pode ser resumida simplesmente em um conceito, mas por um esforço de pensamento, esforço que não depende somente do arbítrio do homem, mas de uma disposição que o perpassa, ou seja: o espanto com o real. Heidegger afirma: "O caminho de nossa discussão deve ser, portanto, de tal tipo e direção que aquilo de que a filosofia trata atinja nossa responsabilidade, nos toque (nous touche), e justamente em nosso ser". (HEIDEGGER, 1973, p.112).

Heidegger compreende a filosofia para além de algo estritamente racional, no sentido cartesiano, mas a própria guardiã da ratio. Para "razão", ele não usa a palavra alemã "Vernunft", mas ratio, termo latino com ressonâncias aristotélicas. A palavra "guardião" em alemão é "Verwalterin", uma palavra que inclui sugestões cruciais para Heidegger, como "cuidadoria" de "custódia ativa" da substância herdada. Porém, para o 
filósofo, isso ainda é uma reflexão superficial, pois mediante a introdução do conceito de "razão" ou "racionalidade", substituímos meramente um problema por soluções históricas da filosofia.

Segundo Heidegger, a própria palavra "philosophía" já transmite consigo algo da experiência inicial do mundo grego, sendo uma via na qual estamos à caminho, um caminho que se estende em nós, para além de nós. Heidegger propõe penetrar no que nos oferece a "philosophía" grega basicamente, retornando o mundo grego como uma forma de resignificar a história do ocidente:

Desta maneira, a palavra grega philosophía é um caminho sobre o qual estamos a caminho. Conhecemos, porém, este caminho apenas confusamente, ainda que possuamos muitos conhecimentos históricos sobre a filosofia grega e os possamos difundir. (...) O caminho para o qual desejaria apontar agora está imediatamente diante de nós. E precisamente pelo fato de ser o mais próximo o achamos difícil. (...) A palavra philosophía está, de certa maneira, na certidão de nascimento de nossa história, a saber, da atual época da história universal que se chama era atômica (HEIDEGGER, 1973, p. 212).

Temos aqui o mais discutido e característico passo no questionamento de Heidegger: a argumentação e a justificação a partir e através da etimologia da palavra. Em seus estudos, o filósofo da floresta negra está sempre preocupado em situar os conceitos filosóficos historicamente, recuperando seu sentido originário, compreendendo o surgi- mento da filosofia e seus desdobramentos. Para Heidegger, é fundamental que avaliemos a importância do filosofar e a "philosophía” já é um caminho para nos conduzir à experiência originária grega do pensar.

Para o autor, não somente a filosofia é grega, como a maneira como ainda formulamos suas questões. Quando perguntamos "o que é isto?", indagamos pela essência do que é "ti estin?", uma interrogação onde os termos são a semente e a articulação dinâmica do pensamento grego, pois não se trata apenas de uma indiscrição, mas sim, é algo que se manifesta a partir do espanto, ou seja, do phatos grego, o que para Heidegger é o princípio originário da filosofia. Quando perguntamos sobre "quididade" (essência) referindo essa indagação como filosófica, somos peculiarmente convidados a retornar ao início grego.

Os gregos já se questionavam sobre: "ti estin", "que é isto?". E através das repostas obtidas sobre o questionamento do objeto nominado "tí estin" se colocava na busca de uma definição do conceito desejado. Assim, quando nos perguntamos "que é isto?", aprofundamos sobre o que é questionado, já estamos fazendo algo que está intimamente ligado com o pensar grego e o princípio originário da filosofia:

Porém, não apenas aquilo que está em questão, a filosofia, é grego em sua origem. Mas também a maneira como perguntamos, mesmo a nossa maneira atual de questionar ainda é grega. Perguntamos: que é isto...? Em grego isto é: tí estin. A questão relativa ao que algo seja permanece, todavia multivoca. Podemos perguntar por perguntar, por exemplo: que é aquilo lá longe? Obtemos então a 
resposta: uma árvore. A resposta consiste em darmos nome a uma coisa que não conhecemos exatamente. (...) A questão de nosso encontro refere-se à essência da filosofia. Se esta questão brota realmente de uma indigência e se não está fadada a continuar apenas um simulacro de questão para alimentar uma conversa, então a filosofia deve terse tornado para nós problemática, enquanto filosofia. É isto exato? Em caso afirmativo, em que medida se tornou a filosofia problemática para nós? Isto evidentemente só pode declarar se já lançamos um olhar para dentro da filosofia. Para isso é necessário que antes saibamos que é isto - a filosofia. Desta maneira somos estranhamente acossados dentro de um círculo. A filosofia mesma parece ser este círculo. Suponhamos que não nos podemos libertar imediatamente do cerco deste círculo; entretanto, é-nos permitido olhar para este círculo. Para onde se dirigirá nosso olhar? A palavra grega philosophía mostra-nos a direção (HEIDEGGER, 1973, p. 213).

Heidegger afirma que a língua grega, diferentemente das demais línguas, nos conduz a uma esfera privilegiada, pois somente ela consegue trazer a experiência do logos. $\mathrm{O}$ Logos não é apenas uma palavra corriqueira para o autor, não podendo ser reduzida a uma questão linguística, embora desde a antiguidade tenha sido interpretado de maneira reducionista, como ratio ou como o que é lógico. O logos é algo que está muito além de tais interpretações pois, para ele, a razão só se traduz na compreensão em sintonia com o logos.

Heidegger prossegue dizendo que a palavra Philósophos foi presumivelmente criada por Heráclito, e que na sua época ainda não havia conhecimento da palavra Filosofia. Assim existe uma distância entre o que Heráclito entendia por Philósophos e que tempos depois, denominou-se Philosophía. O philósophos de Heráclito, para Heidegger, não é igual ao que compreendemos hoje como sendo "filosófico", Philósophos na visão de Heráclito é a experiência humana fundamental, que nos expõe o que chamamos de philein e sophón.

$\mathrm{O}$ anèr philósophos ama o sophón. O que esta palavra diz para Heráclito é difícil traduzir. Podemos, porém, elucidá-lo a partir da própria explicação de Heráclito. De acordo com isto, tá sophón significa: Hèn Pánta 'Um (é) Tudo. Tudo quer dizer aqui: Pánta tà ónta, a totalidade, o todo do ente. Hèn, o Um, designa: o que é um, o único, o que tudo une. Unido é, entretanto, todo o ente no ser. O sophón significa: todo ente é no ser. Dito mais precisamente: o ser é o ente. Nesta locução, o "é" traz uma carga transitiva e designa algo assim como "recolhe". O ser recolhe o ente pelo fato de que é o ente. $\mathrm{O}$ ser é o recolhimento - Logos (HEIDEGGER, 1973, p.215).

Heidegger procura situar a origem das palavras e dos conceitos filosóficos em uma situação ontológica historicamente localizada. Dessa forma, sua análise se concentra inicialmente nas palavras gregas que constituem a filosofia no seu sentido originário. $\mathrm{O}$ significado de filei também para Heidegger não pode apenas ser tomado, de maneira reduzida, como amar ou ser amigo, mas sim de forma radical e objetiva, como uma harmonia um acordo, ou seja, falar da mesma forma que o logos, correspondendo a ele. 
Ele admite que o componente característico de philein pensado por Heráclito é essa harmonia que se revela na recíproca relação de dois seres, nos laços que os unem originalmente numa disponibilidade de um para outro. Da quebra desse acordo, da harmonia, com o sophón surge a filosofia, na Grécia clássica e com ela a pergunta pelo fundamento do ente ("o que é o ente?").

Aristóteles então, quase dois séculos depois de Heráclito, caracterizou este passo com a seguinte afirmação: Kai dê kai tá pálai te kai nyn kai aei zetoúmenon kai aei aporoúmenon, ti tò ón? (Metafísica, VI, 1, 1028 b 2 ss.). Na tradução isso soa: Assim, pois, é aquilo para o qual (a filosofia) está em marcha já desde os primórdios, e também agora e para sempre e para o qual sempre de novo não encontra acesso (e que é por isso questionado): que é o ente? ( $t i$ tò ón) (HEIDEGGGER, 1973, p.216).

Porém, para Heidegger, a forma clássica de se encarar a filosofia e o filosofar, não se encontram mais acessíveis ao logos como em Heráclito e Parmênides. Na visão dele, Heráclito e Parmênides ainda não eram filósofos, mas pensadores originários em harmonia com o logos. E por isso, eles eram "pensadores maiores" no sentido que ainda se situavam no acordo com o logos, apontando para outra dimensão do pensamento.

Os pensadores originários não se perguntavam pela natureza do ente, pois em seus pensamentos ainda imperava o acordo, a harmonia do ente em sua totalidade na physis, e, por isso, ele tinha a coragem de descer às raízes das próprias possibilidades de pensar. Buscando interpretar os modos de ser da realidade, restituindo as estruturas de suas diferenças e a identidade do mistério. Para Heidegger, o espanto é, enquanto páthos, a arkhé da filosofia, compreendido em seu pleno sentido, a palavra grega arkhé designa aquilo de onde algo surge expresso pelo verbo arkhein.

O "espanto" é o que impulsiona a filosofia; e só através dele que é possível o homem encontrar a resposta da pergunta pelo fundamento do ente. Porém, essa resposta deve ser filosófica, algo que nos leve novamente ao caminho que Heidegger afirmou anteriormente.

É importante que o homem, em seu modo de ser Dasein, tenha essa correspondência com o logos, assim como em Heráclito e Parmênides. Porém, a partir da modernidade, para Heidegger, isso não ocorreria mais, pois, segundo ele próprio, esse pathos grego foi substituído pela busca da certeza $e$ do controle do pensamento metafísico clássico.

Autenticidade e ensino: Dasein entre o ensino e a aprendizagem.

Para Heidegger, a abertura fundamental da aprendizagem do mundo pelo Dasein se dá através de três estruturas existenciais: a disposição afetiva, a précompreensão e a linguagem. A disposição afetiva vem primeiro, na qual os entes se mostram e nos afetam. Em seguida, a précompreensão antecipa as interpretações que elaboram as possibilidades projetadas na compreensão e, finalmente, a linguagem regula os pronunciamentos daquilo que nos afetou e foi por nós interpretado. 
Essas três dimensões de abertura do Dasein estão intrinsecamente interligadas; mas há uma nítida prevalência das disposições afetivas, pois nossas interpretações estão impregnadas de afeto e, entre as disposições afetivas, a angústia tem um destaque especial. A angústia é um elemento constituinte da existência do Dasein como ser-nomundo, pois só o ser humano se angustia, não apenas por causa de objetos que o ameaçam, angustia-se pelo fato de estar no mundo, de "ser-jogado" na existência. O Dasein é lançado ao mundo onde se sente estranhamente fora de casa. A angústia, segundo Heidegger, não é somente um fenômeno psicológico e ôntico, trata-se de uma dimensão ontológica do homem, pois nos remete à totalidade da existência como serno-mundo. Ela é a disposição de humor fundamental, privilegiada e original. Somente por ela é possível a abertura do mundo para o Dasein. Com a angústia, abre-se a possibilidade de levar a frente o projeto existencial de ser, ela retira o Dasein da decadência no mundo e revela a possibilidade de ser ele mesmo.

Assim, a angústia é a abertura que atualiza às novas possibilidades do Dasein, sendo ela o movimento e a disposição fundamental com o mundo e possibilidade do ato de ser autêntico. Diz Heidegger: "Na angústia, se está 'estranho'. Com isso se exprime, antes de qualquer coisa, a indeterminação característica em que se encontra a presença na angústia: o nada e o 'em lugar algum'. Mas estranheza significa igualmente 'não se sentir em casa'". (HEIDEGGER, 2002, p. 252)

Só a angústia faz o ser humano sentir a finitude e sua existência, nela o homem encontra a possibilidade de sair da inautenticidade em que geralmente se encontra, para assim assumir sua autenticidade, pois é na angústia que o Dasein confronta-se com a possibilidade de não-ser e, assim, o homem se assume como um ser-para-a-morte (Sein zum tod).

Desse modo, a conclusão da análise fundamental preparatória do Dasein possui como tema "a disposição fundamental da angústia como abertura privilegiada da presença como cura a partir da própria interpretação pré-ontológica da presença, presença mundanidade e realidade, presença, abertura e verdade" (HEIDEGGER, 2002, p. 247).

A análise heideggeriana da angústia diz que é somente por ela que o ser humano pode ter acesso ao nada, o nada é um dos conceitos mais difíceis da compreensão analítica existencial do filósofo da floresta negra, pois tanto pode ser um "nada aniquilador" (nichtiges nichts) que aniquila o que objetivamente existe quanto pode ser considerado como (nichtendes nichts) o nada que é a dimensão misteriosa do próprio ser, por isso nenhum conceito pode representá-lo perfeitamente.

Diante da angústia, o ser humano, suspenso diante do abismo sem fundo do nada, é remetido ao vazio da sua própria finitude, da sua falta e da sua incompletude; por isso, através da angústia, o ser humano pode assumir sua autenticidade, como também pode querer negar o vazio e fugir do nada procurando apoio nos entes e na vida cotidiana moderna. Para Heidegger, os modos de ser inautêntico com que se vive no cotidiano da vida moderna não passam de modos de evitar a angústia. 
Através da angústia, o ser do Dasein mostra-se como cuidado (Sorge). Cuidado do próprio Dasein como ser no mundo $e$ com os outros em geral. O cuidado para Heidegger é um fenômeno ontológico fundamental, pois com ele o homem se preocupa com seu próprio existir e com o existir dos outros em geral. Pois o homem é um ser no mundo que, enquanto Dasein, é também um "ser-com-os-outros" $e$ isso lhe permite uma abertura à convivência, porém esse fenômeno do cuidado apenas se dá em uma temporalidade finita.

O Dasein enquanto "ser-no-mundo" tem uma relação bem forte com os diversos modos de ser intra-mundanos, pois o ser humano relaciona-se tanto com os entes que estão disponíveis ao alcance de suas mãos, como com aqueles que estão dotados com o modo-de-ser do Dasein. Quando não se encontram ao alcance das nossas mãos, eles apenas se colocam diante de nós como realidades dadas, inteiramente independentes do sujeito.

(...) o angustiar-se é um modo de ser-no-mundo; a angústia se angustia com o ser-no-mundo lançado; a angústia se angustia pelo ser-nomundo. Em sua completude, o fenômeno da angústia mostra, portanto, a presença como ser-no-mundo que de fato existe. Os caracteres ontológicos fundamentais desse ente são existencialidade, facticidade $e$ decadência. Essas determinações existenciais, no entanto, não são partes integrantes de um composto, em que se pudesse ou não prescindir de alguma. Ao contrário, nelas se tece um nexo originário que constitui a totalidade procurada do todo estrutural (HEIDEGGER, 2002, p. 255).
Heidegger compreende que essa totalidade se denomina como o cuidado (Sorge) e possui um sentido ontológico, pois é a constituição fundamental do existir humano como abertura originária, no sentido que ilumina tudo o que vêm ao encontro do ser, desde sempre. Com o seu envolvimento com o mundo o ser humano, Dasein, se estrutura em um modo-de-ser que não é um modo isolado, mas compartilhado, pois ele é também um "ser-com-os-outros" (Miteinandersein).

Assim, tudo que o homem pode ou não ser no exercício de sua liberdade, ou ao escolher suas possibilidades, é a própria realização do cuidado (ist eine "Leistung" der Sorge). O cuidado surge como modo-de-ser do Dasein, que procura atualizar as possibilidades de cada um enquanto poder-ser, já que para Heidegger o ser humano é sempre possibilidade para algo.

No terceiro capítulo da segunda parte de Ser e Tempo, Heidegger apresenta a temporalidade como o sentido ontológico do cuidado e com isso entra em confronto com todas as concepções comuns da história da filosofia ocidental, que sempre colocaram o tempo como algo que se desdobra para além do ser humano. Porém, Heidegger concebe essa temporalidade de modo diferente: para ele, a temporalidade não é uma sucessão linear de agoras, uma vez que o passado e o futuro estão entrelaçados no instante presente. O passado não é um nunca mais e não perde jamais o seu vigor de ter sido, pois o que fomos ontem não deixa de estar presente naquilo que somos hoje. Para isso, ele forjou o termo "Gewesenheit" traduzido por "o vigor de ter sido". 
Segundo seu pensamento, o presente é um "Gegenwart'. Nele, as forças de atualização que estão direcionadas para o novo $e$ para o futuro. Entrando em choque com as tendências reativas do passado, o futuro encontra-se no presente como projeto. Essa concepção heideggeriana da temporalidade do tempo presente concentra-se no vigor do ter sido (passado) e no que está por vir (futuro) e, na tensão criada por essas duas forças opostas, forma-se o instante da decisão no qual o homem assume ou recusa o projeto existencial que o define como ser-no-mundo, vivendo uma vida autêntica ou se perdendo no anonimato de uma existência inautêntica do cotidiano moderno.

$\mathrm{O}$ fato de decidir entre a autenticidade e a inautenticidade da existência estão na disposição do homem, ao assumir-se como possibilidade também na possibilidade de impossibilidade de todas as suas possibilidades, ou seja, assumir-se como ser para-amorte. É a morte que dá à existência um sentido de acabamento, pois, quando ela acontece, o "Da" do "Dasein" deixa de ser a luz e a abertura na qual se manifesta o ser dos entes. A morte torna-se a impossibilidade do próprio Dasein, pois, quando ela acontece, não há mais tempo, pois o tempo é propriamente constituído pelo Dasein.

Esta nova maneira de entender a temporalidade humana afirma que a unidade originária da estrutura do cuidado do Dasein reside na temporalidade, pois o ser está sendo e atua na medida em que se temporaliza e se temporaliza nos modos possíveis do si mesmo. Sendo esses modos que possibilitam a pluralidade dos modos-de-ser do Dasein, enquanto vida autêntica ou inautêntica. O Dasein é caracterizado como sendo em um modo-de-ser intimamente ligado a sua finitude e ao seu interrogar. Como um serno-mundo, o homem se encontra lançado sempre a caminho para sua morte.

No texto "Que é uma coisa?", Heidegger afirma que o ensino de filosofia não é somente trabalhar com as ferramentas e conteúdos programados por uma instituição através de seus meios didáticos a fim de viabilizar a correta e eficaz transmissão de conhecimentos específicos. Para o autor, o ensino de filosofia não pode ser apenas pensado da forma tradicional onde o professor é o detentor do conhecimento e o aluno é uma folha em branco a ser preenchida por novos dados e novas informações repassadas pelo professor, o que constitui, na perspectiva heideggeriana, a objetificação de ambos enquanto objetificação dos entes. Educar significa algo mais do que ensinar e cultivar uma erudição cultural, ou ainda transmitir conhecimentos úteis ao cotidiano do aluno. Pensar a educação por esse olhar tende apenas a reduzir e a limitar o pensar e o ensinar. $\mathrm{O}$ saber, nesse sentido, não deve estar à serviço apenas de Estados ou profissões, mas o contrário: o Estado e as profissões deveriam se fundamentar em um saber fundamental, tendo em vista o bem comum. A educação filosófica, nesta perspectiva, pode ocupar-se em compreender o que é ensinar, pois, tratase de uma tarefa cujo sentido é eminentemente filosófico já que trabalha com possibilidades existenciais do próprio aluno enquanto Dasein, sendo o ensino possível em um horizonte de compreensão prévia.

Neste momento inicial, Heidegger se pergunta se é possível ensinar algo a alguém, ou ainda, o que é ensinar? O que é aprender? Ensinar o quê? Ensinar a quem? Heide- 
gger se coloca em torno da pergunta pela possibilidade do ensino, questão persistente e que, segundo o autor, deve ser adotada por todo professor comprometido com seu ofício e pelo seu modo-de-ser-no-mundo refletido em sua atitude na sala de aula com seus alunos. A possibilidade do ensino $e$ aprendizado na reflexão heideggeriana parte do conceito grego mathemata, que segundo o filósofo da floresta negra não pode ser entendido apenas como a tradução simples de matemática, mas deve ser analisado pela etimologia, segundo sua compreensão originária junto aos gregos antigos:

O "matemático", segundo a origem etimológica, resulta do grego tá mathemata, o que se pode aprender e, ao mesmo tempo; em consequência, o que se pode ensinar. Manthanoein significa aprender. Mathesis significa lição e, na verdade, num duplo sentido: lição no sentido de "ir a uma lição e aprender" e lição como "aquilo que é ensinado". Ensinar e aprender são aqui tomados num sentido lato e, ao mesmo tempo, essencial, não no sentido estrito tardio, utilizado na escola pelos doutos (HEIDEGGER, 1987, p. 76).

É segundo esta compreensão de matemático que pode ser entendido a conhecida frase que se encontrava na entrada da Academia de Platão "Afaste-se daqui quem não sabe matemática". A análise apresentada por Heidegger, sobre o lema da academia platônica, poderia ser interpretada como: "Afaste-se daqui quem não se lembrou de sua disposição a aprender". A frase é mais que uma restrição aos que não sabem efetuar cálculos matemáticos, mas sugere uma atitude existencial, tendo em vista a questão do modo de ser do Dasein. A matemática, no sentido que Platão quer direcionar, surge como um pré-requisito para quem deseja, efetivamente, aprender qualquer coisa. $\mathrm{Ou}$ seja, descobrir o aprender como uma atitude. Diz Heidegger: "Mathesis significa aprender; mathemata, o que se pode aprender. De acordo com o que foi dito, as coisas são visadas com esta designação, na medida em que se podem aprender. Aprender é um modo de aprender e do apropriar-se (HEIDEGGER, 1987, p. 76).

Nessa passagem, Heidegger aponta o aprender, em sentido rigoroso e fenomenológico, como algo ainda não pronto, isto é, como um momento que não se conhece, que é superado por um momento seguinte, após ter sido experimentado algum conhecimento. Deste modo, o estudante conhece algo que já tinha alguma expectativa anterior, avançando em busca de um conhecimento cada vez mais abrangente e, por conseguinte, cada vez mais desafiador.

$\mathrm{Na}$ reflexão heideggeriana, a relação com o objeto do aprendizado dá-se a partir de um exercício constante. Essa característica marca o caráter prático do aprender como um dos sentidos do conceito (mathemata), como um exercício que conduz quem aprende a aprender a apreender, sendo a tarefa de apreender algo contínuo, interminável e aberto, como um exercício matemático. Heidegger afirma:

$\mathrm{Na}$ verdade, este "tomar conhecimento" é a essência autêntica do conhecer, a mathesis. As mathematas são as coisas, na medida em que as tomamos no conhecimento, enquanto tomamos conhecimento delas, como aquilo que verdadeira- 
mente já sabemos de modo antecipado: o corpo como corporeidade; na planta, a vegetalidade; no animal, a animalidade; na coisa a coisidade etc. Este verdadeiro aprender é, por consequência, um tomar muito peculiar, um tomar no qual aquele que toma, toma, fundamentalmente, aquilo que já tem. A este aprender corresponde, também, o ensinar. Ensinar é um dar, um oferecer; no ensinar, não é oferecido o ensinável, mas é dada somente ao aluno a indicação de ele tomar aquilo que já tem (HEIDEGGER, 1987, p. 79).

O aprender e o ensinar dá-se em um tipo de relação com os mathematas, no exercício de quem aprende e o que é apreendido. Heidegger afirma que ensinar é indicar a quem deseja aprender aquilo que já se tem, fazendo uma clara referência à fenomenologia, que tem em seus princípios básicos a noção husserliana de que a consciência é sempre consciência de algo. A tarefa e a atitude de quem ensina, o professor, é a de oferecer a oportunidade de o aluno reconhecer em si esta identidade fundamental de buscar sentido à aprendizagem, é provocar e incentivar o aluno a descobrir um sentido próprio a si e a procurar própria necessidade $e$ importância do seu procurar a aprender (finitude e compreensão). O sentido encontrado pelo o aluno é o que o irá orientar em seu horizonte ontológico e revelar uma perspectiva própria a seu projeto existencial $e$ seu acesso ao aprendizado.

Quando o aluno recebe apenas qualquer coisa oferecida, não aprende. Aprende pela primeira vez, quando experimenta aquilo que toma como sendo o que, verdadeiramente, já tem. O verdadeiro apren- der está, pela primeira vez, onde o tomar aquilo que já se tem é um dar a si mesmo e é experimentado enquanto tal [sentido]. Por isso, ensinar não significa senão deixar os outros aprender, quer dizer, um conduzir mútuo até a aprendizagem. Aprender é mais difícil do que ensinar; assim, somente quem pode aprender verdadeiramente - e somente na medida em que tal consegue - pode verdadeiramente ensinar (HEIDEGGER, 1987, p. 79-80).

É preciso, portanto, que o aluno seja incentivado diariamente a se ocupar com a tarefa existencial de descobrir um sentido próprio a si, aprender a colocar-se numa reflexão fenomenológica. Para Heidegger, somente assim o aprendizado é autêntico, pois, o professor diferencia-se do aluno por ter diante de si, de uma maneira mais clara de demonstrar, o aprender. O professor em seu pensamento é quem mais aprende, por também estar aberto a aprender com seus alunos, processo que o autor alemão chamou de um conduzir mútuo até à aprendizagem.

Aprender e ensinar são compreendidos como um conduzir-se a uma esfera originária no qual se pode descobrir um sentido próprio ao Dasein que aprende de maneira temática e curricular sem perder de vista seu sentido originário: possibilitando um sentido orientador-questionador-tematizador de sua existência. Ensinar é ensinar uma "atitude" um "modo-de-ser-no-mundo", ensinar não é somente reproduzir conteúdos curriculares e informações maçantes. Ensinar é algo que envolve atividade diária, é estar aberto $e$ lançado ao movimento do ensinar, do desvelar do Dasein, é tocar no aluno de uma 
forma que o leve a se dirigir ao ethos de todo aprender, a "buscar o caminho" e o sentido de seu aprender.

Esta atitude e postura estão presentes em todos pensadores que, ao longo da história, tiveram êxito em seu processo de ensino aprendizagem, pois aprenderam em um sentido próprio a si primeiramente. Por isso, só faz sentido ensinar quem está pré-disposto (Befindlichkeit) a aprender, a buscar seu conhecimento, e para isso é necessário ter a atitude e o modo-de-ser da palavra grega (mathemata) que está intimamente ligado também ao modo de ser do perguntar como um exercício hermenêutico existencial.

Para Heidegger o que realmente importa na educação filosófica é ter aprendido a aprender por seu próprio modo de ser. Educar, assim como filosofar, deve trazer o homem para perto de si mesmo ressaltando sua relação com o mundo. Isso só é possível a partir do momento em que o perguntar pelo sentido do ser for feito de modo mais íntimo e transparente.

Nesse sentindo, ensinar é ainda mais difícil do que aprender, isso não quer dizer que aquele que ensina deve saber mais do que os que aprendem, o filósofo da floresta negra quer dizer que ensinar significa na verdade convidar alguém a aprender. $\mathrm{O}$ pathos grego é visto como o principal elemento de ligação entre o ser e o mundo.

O processo educacional autêntico é aquele em que alunos aprendem o próprio significado do aprendizado em seu projeto existencial, que é um modo-de-ser questionador da existência. O professor deve ensinar esse convite do perguntar hermenêutico em sala de aula, justamente porque, na educação, não se trata de transmitir apenas con- teúdos. O conhecimento está interligado com o perguntar, sendo este o modo-de-ser do homem, e seu modo-de-ser por excelência se dá na existência provisória e finita.

Nesse sentido, conhecer é uma espécie confraternização com as coisas, com que estão ao seu entorno e no mundo. Porém se quisermos colocar a pergunta sobre um possível ensinar ou conhecer segundo Heidegger, é preciso primeiramente ver até onde podemos caminhar com essa pergunta. É essencial entender que o modo-de-ser do Dasein se constitui na existência pois viver também é conhecer.

É preciso voltar aos pensadores originários que se espantavam com a existência $e$ tratar a filosofia, o aprender e o conhecimento, sem tentar dar uma resposta definida, absoluta sobre o sentido do Ser. É necessário voltarmos a ver os fenômenos como aquilo que se mostra em seu desvelamento existencial. Isso só é possível através do exercício hermenêutico do Dasein, esse único ente privilegiado que possui tanto uma abertura ôntica como uma abertura préontológica da existência. Trata-se agora pensar diferente e de trabalhar a dificuldade em ver como se fosse pela primeira vez aquilo que estava em baixo de nosso nariz o tempo todo $e$ foi esquecido pela tradição metafisica, o que o autor chama de ocultamento do Ser, sua temporalidade e seu modo-de-ser no mundo, o Dasein assim torna-se o único ente para qual as coisas podem aparecer e se desvelar. É preciso se espantar novamente e se perguntar com essa questão fundamental da existência, pois esse é o modo-ser-ser que constitui o homem, a possibilidade e respectivamente necessidade de ser aberto ao sentido autêntico e ontológico da finitude. É 
nessa abertura que se encontra a sala de aula, onde ser humano mostra-se e se faz, pois existe uma instância e um acontecimento de seu modo-de-ser; é somente nessa abertura que existe a possibilidade de um lugar onde toda realidade é possível e pode se tornar conhecimento e transcendência.

Em vários de seus textos, Heidegger já expunha esse pensamento, na medida em que clamava a seus ouvintes o se deixar levar por uma relação questionadora com o ser, relação esta que só pode acontecer quando deixamos de ser "animal de rebanho", como dizia Nietzsche, e começamos a pensar por nossa própria conta, nos colocando novamente diante do que talvez seja o coração de toda filosofia. O perguntar e o questionar não se baseiam somente em uma atitude que precede sempre uma resposta ou um saber. O modo-de-ser do questionar, pelo contrário, torna-se em si mesmo a figu- ra em que o saber se estabelece, exposto ao que é incerto e problemático e digno de ser posto em questão.

A relevância do pensamento Heidegger está na grande preocupação do Dasein com sua forma de ser-no-mundo, que, para viver bem a sua própria humanidade, precisa antes de tudo fazer uma análise hermenêutica do existir e de seu questionar. Heidegger nos põe a refletir sobre um modo de ensino que convide o aluno a aprender. Não a aprender o que um determinado autor quer afirmar. Mas sim aprender a aprender $e$ a questionar de forma pessoal seu próprio fenômeno existencial.

\section{Referências}

HEIDEGGER, M. Ensaios e conferências. Petrópolis/ Bragança Paulista: Vozes/Editora Universitária São Francisco, 2008.

Ser e Tempo. Petrópolis: Vozes, 2002. 1973.

Conferências e escritos filosóficos. Coleção 'Os Pensadores'. São Paulo: Abril Cultural, Que é uma coisa? Tradução de Carlos Morujão. Lisboa: Edições 70, 1987.

Recebido em: $25 / 05 / 2020$

Aprovado em: 22/10/2020 